Article

\title{
Evaluating R\&D and Transformation Functional Platforms' Operational Performance Using a Data Envelopment Analysis Model: A Comparative Study
}

\author{
Yuhong Cao ${ }^{1}$, Jianxin You ${ }^{2}$, Yongjiang $\mathrm{Shi}^{3}$ and Wei $\mathrm{Hu}^{4, *}$ \\ 1 School of Management, Shanghai University, 99 Shangda Road, BaoShan District, Shanghai 200444, China; \\ caoyuhong@shu.edu.cn \\ 2 School of Economics \& Management, Tongji University, 1239 Siping Road, Shanghai 200092, China; \\ yjx2256@tongji.edu.cn \\ 3 Institute for Manufacturing, University of Cambridge, Cambridge CB30FS, UK; ys@eng.cam.ac.uk \\ 4 School of Economics and Trade, Shanghai Urban Construction Vocational College, 2080 Nanting Road, \\ Fengxian District, Shanghai 201415, China \\ * Correspondence: huwei@succ.edu.cn; Tel.: +86-189-1827-1545
}

Received: 8 August 2019; Accepted: 6 September 2019; Published: 13 September 2019

\begin{abstract}
The purpose of this paper is to provide a contribution to the development of $R \& D$ and transformation functional platforms by identifying key performance influencing factors in the use of data envelopment analysis (DEA) to analyze platform operation performance status and reasons. The DEA method is undertaken to calculate the comprehensive efficiency, pure technical efficiency and scale efficiency of R\&D and transformation functional platforms in China's 30 provinces within the period 2016-2018. Based on the 2018 pure technical efficiency and scale efficiency calculations, the K-means clustering method was used to classify the R\&D and transformation functional platforms of 30 provinces. Finally, according to the clustering results, the corresponding clustering improvement scheme is given. The operational level of R\&D and transformation functional platforms in many provinces of China still needs to be improved: the $R \& D$ and transformation capabilities are weak, the market share of leading products is low, the ability of new technology value-added is insufficient, and the development of R\&D and transformation functional platforms has regional imbalance. This study is based solely on statistical data, these data alone obviously cannot fully describe and evaluate the real state of R\&D and transformation functional platform due to the complexity and diversity of platforms. Further research is needed to generalize beyond the performance indicators constructed in this paper. For the problems of low overall operation efficiency, unbalanced regional development, redundancy of input resources and lack of professional management personnel in the operation of R\&D and transformation functional platforms, policy suggestions can be put forward according to clustering results and input and output adjustment values calculated based on relaxation variables. The study presenting a methodology for analyzing R\&D and transformation functional platforms' operation performance, and the conclusions will provide reference for the development of platforms and high-tech industries.
\end{abstract}

Keywords: R\&D and transformation functional platform; performance evaluation; DEA

\section{Introduction}

$R \& D$ and transformation functional platform is a powerful complement to the high-tech industrial cluster at the present stage, it integrates the resources of all links and entities in the high-tech industry value chain effectively and safely, and realizes the common demand of high-tech industry chain innovation, major R\&D transformation and service innovation as well as the industrial chain 
cluster innovation. As a core organization in the field of innovation, $R \& D$ and transformation functional platform provide a basic environment or condition support for various innovation entities in different innovation or value add links. In 2018, 3217 R\&D and transformation functional platforms were included in the National Science and Technology Infrastructure Platform Center Program, including 459 provincial-level and ministerial-level platforms, with 72,000 employees and nearly 10,000 internal innovation institutions. In 2018 alone, the value of scientific and technological achievements transformation exceeded 3 billion yuan. While great achievements have been made, there are still many problems which China's $R \& D$ and transformation functional platforms need to overcome, such as high transaction costs lead by specialized division of labor, insufficient open public services, and unbalanced distribution of innovation resources. Evaluating the performance of R\&D and transformation functional platforms in various provinces can further find the specific operation problems and the performance differences at the regional level, the finally operational improvement suggestions based on these scientific analyses will have more targeted and more conducive to shaping a good platform ecological environment.

Foreign research on the performance of R\&D and transformation functional platforms mostly focuses on building a performance evaluation system and conducting empirical analysis in combination with survey data. Adner [1] used the three-dimensional triangular prism model to set up a performance evaluation system based on five key elements: the satisfaction of stakeholders, the contribution of stakeholders, organizational strategy, business process and organizational capabilities. Proskuryakova [2] and Fraccascia [3] believe that effective internal operations management mechanism is the key to the success of R\&D and transformation functional platforms. Berghe [4] evaluated platform's performance based on input-output relationship of platform innovation transformation process and the cooperation and information transfer among partners. Cai [5] uses productivity, vitality and gap market creativity to evaluate platform performance and points out that a healthy and sustainable management mechanism is essential for a successful R\&D and transformation functional platforms. Armando [6] and Choi [7] believe that a sound performance evaluation mechanism needs to combine platform's R\&D experience, challenges, R\&D skill level, and the overall operating environment. Astyne [8] and Mačiulienè [9] believe that the basic services and value-added services provided by platform should be set as the core performance content.

Many domestic scholars have also carried out related research. Zhang [10] put forward the notion of performance evaluation indicators from the perspective of ecology, and believes that scientific research innovation ability, symbiosis level, conversion efficiency and growth environment factor are the main factors affecting platform's healthy operation, and used fuzzy comprehensive evaluation method to conduct an empirical research. Li\&Zhang [11] proposed to measure the operational efficiency of regional platforms from four dimensions: innovation vitality, structural optimization, ecological resilience and service function, and established a fuzzy matter element closeness model to evaluate its performance level. Yin [12] discussed the connotation and characteristics of the R\&D and transformation functional platform, based on this, a comprehensive evaluation index system was constructed, and its performance status was analyzed by fuzzy comprehensive evaluation method (FAHP). Wang [13] established a performance evaluation index system from three dimensions: system vitality, system organization and system flexibility. Li [14] believes that the government, trustee, small and medium-sized enterprises, and platform technical service personnel are the most important stakeholders in the R\&D and transformation functional platform, therefore, the harmonious symbiosis relationship based on multi-stakeholder cooperation and complementarity is the foundation for ensuring platform development with high-performance operation.

At present, research on R\&D and transformation functional platforms' operational performance has attracted widespread attention and achieved certain results, but there are still some limitations. The first limitation is that most existing research only calculates the operational efficiency value of a single R\&D and transformation functional platform in a certain region, the comparative analysis is lacking and the final policy recommendations are less targeted. The second limitation is, most performance indicators 
set by the existing research are qualitatively evaluated from the perspectives of synergy among subjects or R\&D level, and there have no quantitative data, which cannot well reflect platforms specific development in different regions after the implementation of innovation-driven development strategy.

This paper intends to build an index system as follows: the input indicators are the number of researchers (as indicators of human resources input), the number of R\&D and technical service institutions (as indicators of material resources input), and the total R\&D funds (as indicators of financial resources input); the output indicators are the total value of technological achievements transformation, the market share of leading products, industrial output value of new products and the number of authorized invention patents. Based on the data from 2016 to 2018, a DEA model was built to analyze the performance of R\&D and transformation functional platforms in China's 30 provinces. On the basis of the calculated operational efficiency value in 2018 , the sustainable and healthy development plan of platforms in various regions is put forward by using the methods of cluster analysis, input and output adjustment. Compared with the existing research, the possible innovative work of this paper is embodied in the following aspects: (1) Based on the provincial perspective, efficiency of R\&D and transformation functional platforms and their decomposition indicators are compared and analyzed, which to some extent makes up for the lack of research in this field, and deepens the theoretical and empirical research on platforms' innovation efficiency improvement; (2) Expanding the research perspective of innovation efficiency influencing factors, systematically explore the path that affects the innovation efficiency from three perspectives of clustering, input and output, and on this basis, putting forward a program to enhance the innovation efficiency of $R \& D$ and transformation functional platforms.

The remainder of the paper is organized as follows: in Section 2, evaluation model is constructed and an index system set up; then, an empirical analysis is performed and discussed in Section 3; in Section 4, performance improvement programs have been proposed and a Conclusions and Recommendations section ends the paper.

\section{Model Construction}

\subsection{Model Selection}

Data Envelopment Analysis (DEA) can evaluate the relative efficiency of homogeneous decision-making units with multiple inputs and multiple outputs, and also can effectively estimate the production frontier. DEA has obvious advantages compared with other methods, for example, DEA method only need the input and output data of original decision unit without needing to pre-estimate the production function of each decision unit. In addition, DEA is used to evaluate the relative efficiency between decision-making units, that is, using the weighted sum ratio between the output and input of decision-making unit as the optimization model, so that the optimal input and output weights of each decision-making unit can be obtained through planning without giving the relevant input and output weights beforehand, which can effectively avoid the influence of subjective factors on evaluation results.

The representative models in DEA theory are CCR-DEA model, BCC-DEA model and SBM-DEA model. SBM model is a non-radial model, which cannot realize that all inputs or outputs of the same decision-making unit can be reduced or increased in the same proportion and projected to the effective frontier. Both the CCR model and the BCC model are radial models, but the CCR model basically assumes that the scale returns are constant. In reality, the performance activities of $R \& D$ and transformation functional platforms are often difficult to satisfy the assumption that scale rewards remain unchanged due to the comprehensive influence of many factors, such as national policy regulation, external environmental effects and so on. Therefore, this study uses BCC model with variable scale reward as basic assumption to evaluate the operational efficiency of R\&D and transformation functional platforms in various provinces. 
Suppose there are $p$ decision-making units (DMU), each DMU has $m$ kinds of input indicators and $n$ kinds of output indicators. $x_{i j}$ is the $i$-th input of the $j$-th DMU, $y_{r j}$ is the $r$-th output of the $j$-th DMU, where: $i=1,2, \ldots, m ; r=1,2, \ldots, n$. The weight coefficients of various inputs and outputs of the $j$-th DMU are expressed as $\lambda_{j}$. The relaxation variables of the $i$-th input and the $r$-th output are expressed as $S_{j}^{-}$and $S_{r}^{+}$, respectively, and the relative efficiency of DMU is expressed as $\theta$. The BCC model is constructed as follows:

$$
\begin{gathered}
\min \theta-\varepsilon\left(\sum_{i=1}^{m} S_{i}^{-}+\sum_{r=1}^{n} S_{r}^{+}\right) \\
\sum_{j=1}^{p} \lambda_{j} x_{i j}+S_{i}^{-}=\theta x_{i 0} \\
\sum_{j=1}^{p} \lambda_{j} x_{i j}+S_{r}^{+}=\theta y_{r 0} \\
\sum_{j=1}^{p} \lambda_{j}=1 \\
\lambda_{j}, S_{i}^{-}, S_{r}^{+} \geq 0 \\
i=1,2, \cdots, m ; r=1,2, \cdots, n ; j=1,2, \cdots, p
\end{gathered}
$$

Compared to the CCR model, the BCC model has an additional $\sum_{j=1}^{p} \lambda_{j} y_{r j}=1$ constraint that relaxes the cone axiom hypothesis in CCR model. By solving the optimal solution of Equation (1), the DEA validity of each decision unit can be judged. If the optimal solution in the model is: $\theta=1$, $S_{j}^{-}=0, S_{r}^{+}=0$, then the DMU is valid; if the optimal solution, the DMU is invalid.

First, the overall performance of each region's R\&D and transformation functional platform is calculated by BCC model, then, the overall performance is decomposed into pure technical efficiency and scale efficiency. Pure technical efficiency means that the current resource utilization has reached the best when the scale returns are the same. That is to say, no matter how much input is added, the output will not increase. In other words, the current input is the best input. Scale validity means that under the condition of constant input level of R\&D and transformation functional platforms, the existing scale of platforms in these provinces can achieve the greatest benefits, and further expanding or reducing its scale will only result in lower operational efficiency.

\subsection{Index System Construction}

Scientific and reasonable index selection is the basis of effective evaluation. Draws on the existing literature and consummate through field interviews and research, this study constructs a performance evaluation index system of $R \& D$ and transformation functional platform as shown in Table 1.

In terms of input indicators, the resources needed for R\&D and transformation functional platforms' normal operation are investigated from three aspects: number of core researchers, R\&D and technical service institutions, and total $R \& D$ funds. The number of core researchers is measured by number of major scientific research personnel in R\&D and transformation functional platform. The core researcher refers to the R\&D personnel who have advantages in $R \& D$ capability, innovation resources and cooperation experience in the platform. Their number directly determines the status of R\&D and transfer system and knowledge sharing system, and then affects platform's final performance [15].

Number of R\&D and technical service institutions refer to the number of R\&D and technical service institutions constructed or introduced in platform system, including $R \& D$ achievements transformation, technical transaction and consulting institutions, as well as related engineering and technical research centers, key laboratories, etc. The more institutions, the more resources the platform has, the more conducive to improving platform's performance [16]. The total amount of R\&D capital funds refers to the sum of government investment and venture capital obtained by platform in that year. R\&D investment should focus not only on the existing market prospects, but also on supporting future 
industry, common technology and core technology R\&D [17]. The amount of investment determines platform's development mode at this stage, and also determines the future development strategy [18].

Table 1. R\&D and transformation functional platform operation performance evaluation index system.

\begin{tabular}{|c|c|c|}
\hline Primary Indicator & Secondary & ndicators and Description \\
\hline \multirow{3}{*}{ Input indicator } & Number of researchers & $\begin{array}{l}\text { Number of core researchers in R\&D and } \\
\text { transformation functional platforms }\end{array}$ \\
\hline & $\begin{array}{l}\text { Number of R\&D and technical } \\
\text { service institutions }\end{array}$ & $\begin{array}{l}\text { The more R\&D and technical institutions, the } \\
\text { richer resources the platform has and the } \\
\text { healthier it will be. }\end{array}$ \\
\hline & Total R\&D funds & $\begin{array}{l}\text { The sum of government investment and venture } \\
\text { capital obtained by platform in that year }\end{array}$ \\
\hline \multirow{4}{*}{ Output indicator } & $\begin{array}{l}\text { Total value of technical } \\
\text { achievements transformation }\end{array}$ & Technical market contract amount \\
\hline & Market share of leading products & $\begin{array}{l}\text { The ratio of platform-led products to domestic } \\
\text { market in the previous year }\end{array}$ \\
\hline & $\begin{array}{l}\text { Industrial output value of new } \\
\text { products }\end{array}$ & $\begin{array}{l}\text { The ratio of output value of new products to the } \\
\text { total output value in the previous year }\end{array}$ \\
\hline & $\begin{array}{l}\text { Number of authorized invention } \\
\text { patents }\end{array}$ & $\begin{array}{l}\text { The number of patents granted by platform at } \\
\text { home and abroad in the previous year, including } \\
\text { the number of software copyright registrations }\end{array}$ \\
\hline
\end{tabular}

In terms of output indicators, this paper examines from four aspects: total value of technological achievements transformation, market share of leading products, industrial output value of new products and number of authorized invention patents. The total value of technological achievements transformation is measured by the contract amount of technology market. The number of patent conversions, the number of patents and their conversions that meet market demand, and the utilization of basic common technologies and achievements will not only affect the waste of platform resources, but also affect the completion of platform's initial strategic objectives. Therefore, the total value of technological achievements transformation directly reflects platform overall performance [19]. The market share of leading products refers to market share of leading products in ecosystem of the previous year, and the new product output value ratio refers to the ratio of new product output value in the ecosystem of the previous year to its total output value. The market share and products output value are not only the direct reflection of customers' acceptance of products, but also the indirect reflection of platform innovation and transformation efficiency [15]. The number of authorized invention patents refers to the number of all invention patents obtained by platform in the previous year (including the number of software copyright registrations). The more patents, the higher innovation performance within the platform [20].

\subsection{Data Sources}

The relevant data of input and output indicators of $R \& D$ and transformation functional platforms in 30 provinces from 2016 to 2018 come to China's S\&T statistical yearbook issued by the National Statistical Bureau (China Science and Technology Statistics Yearbook 2016, China Science and Technology Statistics Yearbook 2017, China Science and Technology Statistics Yearbook 2018) and the annual statistical reports issued by the provincial and municipal S\&T infrastructure platform centers. Due to the lack of data in some provinces and municipalities, only 30 provincial regions were analyzed in this study. 


\section{Empirical Analysis}

\subsection{Descriptive Statistical Analysis}

Descriptive statistics is used to analyze the data of R\&D and transformation functional platforms in different provinces from 2016 to 2018, the results are shown in Table 2. As can be seen from Table 2, the operational performance of $R \& D$ and transformation functional platforms in 30 provinces is quite different. The maximum value of overall efficiency is 1.000 , the minimum value is 0.378 , the average value is 0.784 , and the standard deviation is 0.178 . In terms of input indicators, the standard deviation of the total number of researchers, $R \& D$ and technical service institutions and R\&D funds is large, indicating that there are great differences in platform operation investment in various provinces. In terms of output indicators, the standard deviation of total value of technical achievements transformation, market share of leading products, industrial output value of new products, number of authorized invention patents is large, which indicates that the output of R\&D and transformation functional platforms in different provinces is quite different, and the average value of these output indicators is not high, indicating that platforms output still needs to be increased.

Table 2. Descriptive statistical analysis.

\begin{tabular}{|c|c|c|c|c|c|}
\hline Variable & Mean & $\begin{array}{c}\text { Standard Error } \\
\text { of Mean }\end{array}$ & $\begin{array}{l}\text { Standard } \\
\text { Deviation }\end{array}$ & $\begin{array}{l}\text { Minimum } \\
\text { Values }\end{array}$ & $\begin{array}{l}\text { Maximum } \\
\text { Values }\end{array}$ \\
\hline The overall efficiency (TE) & 0.874 & 0.029 & 0.178 & 0.378 & 1.000 \\
\hline Pure technological efficiency (PTE) & 0.922 & 0.027 & 0.159 & 0.387 & 1.000 \\
\hline Scale efficiency (SE) & 0.957 & 0.020 & 0.094 & 0.691 & 1.000 \\
\hline Number of researchers & 137 & 34 & 174 & 54 & 218 \\
\hline Number of R\&D and technical service institutions & 12 & 15 & 21 & 8 & 32 \\
\hline Total R\&D funds & $26,543,670$ & $3,686,230$ & $35,539,850$ & 58,990 & $212,659,320$ \\
\hline $\begin{array}{l}\text { The total value of technical achievements } \\
\text { transformation }\end{array}$ & $29,889,976$ & $3,774,397$ & $36,377,355$ & 694,165 & $232,831,926$ \\
\hline Market share of leading products & 0.132 & 0.006 & 0.057 & 0.030 & 0.317 \\
\hline Output value of new products & 0.031 & 0.005 & 0.034 & 0.017 & 0.106 \\
\hline Number of authorized invention patents & 627 & 143 & 706 & 69 & 2103 \\
\hline
\end{tabular}

\subsection{Dea Efficiency Analysis}

The performance of R\&D and transformation functional platforms in different provinces from 2016 to 2018 was measured by Deap 2.1 software, and the results are shown in Table 3. It can be seen from Table 3 that among 30 provinces, there are 15 provinces' $R \& D$ and transformation functional platforms operating efficiency DEA is effective in 2016; there are 18 provinces' $R \& D$ and transformation functional platforms operating efficiency DEA is effective in 2017; there are 14 provinces' $R \& D$ and transformation functional platforms operating efficiency DEA is effective in 2018; In Anhui, Henan and Hubei provinces, the efficiency of platforms has been reduced from effective to ineffective. The operational efficiency of platforms in Guangxi, Hebei, Hainan, Jiangxi, Gansu and Ningxia provinces has increased year by year. Fujian, Guizhou, Heilongjiang, Liaoning and other provinces R\&D and transformation of functional platforms operating efficiency shows a fluctuating state. It can be concluded that platforms' operation in most provinces of China is still in the initial stage, their efficiency is low, and the R\&D and transformation need to be improved. At the same time, the development of platform has a large regional imbalance problem due to the difference of platform ecological environment in different regions. 
Table 3. Operational efficiency of R\&D and transformation functional platforms in different provinces from 2016 to 2018.

\begin{tabular}{|c|c|c|c|c|c|c|c|c|c|}
\hline \multirow{2}{*}{ Province } & \multicolumn{3}{|c|}{2016} & \multicolumn{3}{|c|}{2017} & \multicolumn{3}{|c|}{2018} \\
\hline & TE & PTE & SE & TE & PTE & SE & TE & PTE & SE \\
\hline Anhui & 1.00 & 1.00 & 1.00 & 1.00 & 1.00 & 1.00 & 0.96 & 0.96 & 1.00 \\
\hline Beijing & 1.00 & 1.00 & 1.00 & 1.00 & 1.00 & 1.00 & 1.00 & 1.00 & 1.00 \\
\hline Chongqing & 1.00 & 1.00 & 1.00 & 1.00 & 1.00 & 1.00 & 1.00 & 1.00 & 1.00 \\
\hline Fujian & 0.77 & 0.88 & 0.87 & 0.75 & 0.87 & 0.86 & 0.91 & 1.00 & 0.91 \\
\hline Jilin & 1.00 & 1.00 & 1.00 & 1.00 & 1.00 & 1.00 & 0.71 & 0.71 & 0.99 \\
\hline Gansu & 0.43 & 0.49 & 0.87 & 0.51 & 0.65 & 0.79 & 0.48 & 0.68 & 0.70 \\
\hline Guangdong & 1.00 & 1.00 & 1.00 & 1.00 & 1.00 & 1.00 & 1.00 & 1.00 & 1.00 \\
\hline Guangxi & 0.64 & 0.64 & 1.00 & 0.71 & 0.81 & 0.88 & 0.78 & 0.78 & 1.00 \\
\hline Guizhou & 0.53 & 0.65 & 0.82 & 0.86 & 1.00 & 0.86 & 0.77 & 0.93 & 0.83 \\
\hline Hebei & 0.67 & 0.68 & 0.98 & 0.70 & 0.85 & 0.82 & 0.89 & 1.00 & 0.89 \\
\hline Henan & 1.00 & 1.00 & 1.00 & 1.00 & 1.00 & 1.00 & 0.89 & 1.00 & 0.89 \\
\hline Heilongjiang & 0.49 & 0.53 & 0.92 & 0.57 & 0.69 & 0.82 & 0.50 & 0.51 & 0.99 \\
\hline Hubei & 1.00 & 1.00 & 1.00 & 1.00 & 1.00 & 1.00 & 0.73 & 0.81 & 0.90 \\
\hline Hunan & 1.00 & 1.00 & 1.00 & 1.00 & 1.00 & 1.00 & 1.00 & 1.00 & 1.00 \\
\hline Hainan & 0.80 & 0.80 & 1.00 & 1.00 & 1.00 & 1.00 & 1.00 & 1.00 & 1.00 \\
\hline Jiangxi & 0.86 & 0.88 & 0.98 & 0.88 & 0.88 & 1.00 & 1.00 & 1.00 & 1.00 \\
\hline Jiangsu & 1.00 & 1.00 & 1.00 & 1.00 & 1.00 & 1.00 & 1.00 & 1.00 & 1.00 \\
\hline Liaoning & 0.68 & 0.88 & 0.80 & 0.65 & 0.83 & 0.78 & 0.80 & 0.83 & 0.96 \\
\hline Inner Mongolia & 0.73 & 0.86 & 0.85 & 0.81 & 0.81 & 1.00 & 0.77 & 0.89 & 0.87 \\
\hline Ningxia & 0.76 & 0.76 & 1.00 & 1.00 & 1.00 & 1.00 & 1.00 & 1.00 & 1.00 \\
\hline Qinghai & 0.80 & 1.00 & 0.80 & 0.91 & 0.91 & 1.00 & 0.66 & 0.83 & 0.80 \\
\hline Shanxi & 1.00 & 1.00 & 1.00 & 1.00 & 1.00 & 1.00 & 1.00 & 1.00 & 1.00 \\
\hline Shandong & 1.00 & 1.00 & 1.00 & 1.00 & 1.00 & 1.00 & 1.00 & 1.00 & 1.00 \\
\hline Shanghai & 1.00 & 1.00 & 1.00 & 1.00 & 1.00 & 1.00 & 1.00 & 1.00 & 1.00 \\
\hline Shaanxi & 0.77 & 0.77 & 1.00 & 1.00 & 1.00 & 1.00 & 0.78 & 1.00 & 0.78 \\
\hline Sichuan & 0.79 & 1.00 & 0.79 & 0.77 & 0.94 & 0.82 & 0.76 & 0.78 & 0.97 \\
\hline Tianjin & 1.00 & 1.00 & 1.00 & 1.00 & 1.00 & 1.00 & 1.00 & 1.00 & 1.00 \\
\hline Xinjiang & 0.63 & 0.80 & 0.79 & 0.92 & 1.00 & 0.92 & 0.63 & 0.81 & 0.78 \\
\hline Yunnan & 1.00 & 1.00 & 1.00 & 1.00 & 1.00 & 1.00 & 1.00 & 1.00 & 1.00 \\
\hline Zhejiang & 1.00 & 1.00 & 1.00 & 1.00 & 1.00 & 1.00 & 1.00 & 1.00 & 1.00 \\
\hline
\end{tabular}

Note: TE, PTE, and SE represent the overall efficiency, R\&D efficiency and conversion efficiency of innovation results respectively, TE $=$ PTE ${ }^{*} \mathrm{SE}$.

\section{Performance Improvement Plan}

\subsection{Overall Improvement Program}

Based on the relevant index data of 2018, the K-means clustering analysis method was used to analyze DEA efficiency values of R\&D and transformation functional platforms in each province in 2018. When using K-means clustering analysis, set clustering variables to pure technical efficiency and scale efficiency (pure technical efficiency is not related to scale efficiency), set the clustering number $\mathrm{K}$ to 4. SPSS 21.0 is used to process and sort out the output results, as shown in Table 4.

Table 4. Cluster Analysis.

\begin{tabular}{cccccccccc}
\hline \multirow{2}{*}{ Clustering Variable } & \multicolumn{4}{c}{ Initial Clustering Center } & \multicolumn{4}{c}{ Final Cluster Center } \\
\cline { 2 - 9 } & I & II & III & IV & I & II & III & IV \\
\hline PTE & 1.000 & 1.000 & 0.724 & 0.475 & 0.991 & 1.000 & 0.769 & 0.483 \\
SE & 1.000 & 0.727 & 0.903 & 0.998 & 0.986 & 0.761 & 0.941 & 0.995 \\
\hline Note: PTE and SE represent pure techno
\end{tabular}


As can be seen from Table 4: the pure technical efficiency and scale efficiency of R\&D and transformation functional platform in provinces of category I are both high, belongs to the highest comprehensive efficiency; the scale efficiency of R\&D and transformation functional platforms in category II provinces is lower than pure technical efficiency; the pure technical efficiency and scale efficiency of R\&D and transformation functional platforms in category III provinces are all at a low level; the scale efficiency of R\&D and transformation functional platforms in provinces of category IV is obviously higher than that of pure technical efficiency.

It can be seen from Table 5 that the significance level of the two clustering variables of pure technical efficiency value and scale efficiency value are both 0.000 , under the $5 \%$ significance level, clustering results pass significance test. Therefore, based on this clustering result, operational efficiency of R\&D and transformation functional platforms in 30 provinces across the country can be classified and analyzed, the result are shown in Table 6.

Table 5. K-means Clustering Variance Analysis.

\begin{tabular}{|c|c|c|c|c|c|c|}
\hline $\begin{array}{l}\text { Clustering } \\
\text { Variables }\end{array}$ & \multicolumn{2}{|c|}{ Mean Square between Groups } & \multicolumn{2}{|c|}{ Mean Squares within Group } & $\begin{array}{c}\text { F } \\
\text { Value }\end{array}$ & $\begin{array}{c}\text { Significant } \\
\text { Level }\end{array}$ \\
\hline PTE & 0.211 & 3 & 0.001 & 26 & 310.125 & 0.000 \\
\hline SE & 0.032 & 3 & 0.001 & 26 & 30.931 & 0.000 \\
\hline
\end{tabular}

Note: PTE and SE represent pure technical efficiency and scale efficiency respectively.

Table 6. Classification results of China's R\&D and transformation functional platforms operational efficiency.

\begin{tabular}{cccc}
\hline Category I & Category II & Category III & Category IV \\
\hline $\begin{array}{c}\text { Anhui, Beijing, Chongqing, Fujian, } \\
\begin{array}{c}\text { Guangdong, Hebei, Henan, Hunan, Hainan, } \\
\text { Jiangxi, Jiangsu, Ningxia, Shanxi, Shandong, } \\
\text { Shanghai, Tianjin, Yunnan, Zhejiang }\end{array}\end{array}$ & $\begin{array}{c}\text { Guizhou, } \\
\text { Inner Mongolia, } \\
\text { Shaanxi }\end{array}$ & $\begin{array}{c}\text { Gansu, } \\
\text { Qinghai, } \\
\text { Xinjiang }\end{array}$ & $\begin{array}{c}\text { Jilin, Guangxi, } \\
\text { Heilongjiang, Hubei, Liaoning, } \\
\text { Sichuan }\end{array}$ \\
\hline
\end{tabular}

On the basis of cluster analysis, the rationality of above grouping is tested by $\beta$-convergence. The $\beta$-convergence is divided into conditional $\beta$-convergence and absolute $\beta$-convergence. The conditional $\beta$-convergence is used to test whether the platform efficiency of a single province in the evaluation group tends to its steady-state level over time. On the basis of absolute $\beta$-convergence, conditional $\beta$-convergence requires introducing vector $K_{j, t}$ to control the cross-regional variation of steady-state values. The regression equations for the absolute $\beta$-convergence model and conditional $\beta$-convergence model is set as follows:

$$
\begin{gathered}
\log \left(E_{j, t+1} / E_{j, t}\right)=a-b \log \left(E_{j, t}\right)+u_{j, t, t+1} \\
\log \left(E_{j, t+1} / E_{j, t}\right)=a-b \log \left(E_{j, t}\right)+\varphi K_{j, t}+u_{j, t, t+1}
\end{gathered}
$$

where: $\mathrm{E}_{j, t}, \mathrm{E}_{j, t+1}$ are the efficiency of provinces $j$ at $t$ year and $t+1$ year, $a$ is a constant term, $u_{j, t, t+1}$ is a random disturbance term $(j=1,2,30 ; t=2016,2017,2018)$, if the regression coefficient is less than zero, then the convergence exists. A vector $K_{j, t}$ that exerts control over the variation of the steady-state value across regions is introduced in Equation (3). The result is shown in Table 7.

The test results show that there are absolute convergence and relative convergence within the four different categories provinces. That is, the platform's efficiency between different provinces tends to be consistent within each category, and the efficiency of each province also maintains a relatively stable level. Convergence test results verify the rationality clustering. 
Table 7. $\beta$-Convergence test results.

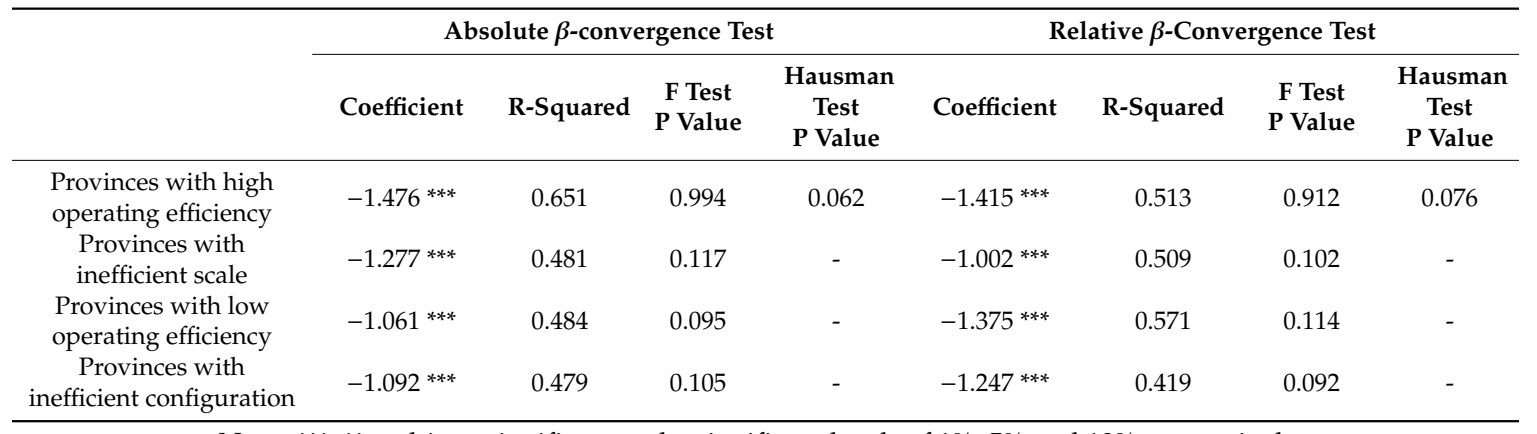

Note: ${ }^{* * *},{ }^{* *}$ and $*$ are significant at the significant levels of $1 \%, 5 \%$ and $10 \%$, respectively.

(1) Provinces with high operating efficiency of $R \& D$ and transformation functional platforms. These provinces belongs to category I in the cluster analysis, and its pure technical efficiency and scale efficiency are equal to 1 or very close to 1.18 provinces fall into this category, accounting for $60 \%$ of the total. Among them, Beijing, Chongqing, Guangdong, Hunan, Hainan, Jiangxi, Jiangsu, Ningxia, Shanxi, Shandong, Shanghai, Tianjin, Yunnan and Zhejiang are 14 provinces which platforms' pure technical efficiency, scale efficiency and comprehensive efficiency are all 1, that is to say, the current resources utilization in these provinces has been the best, and income that can be achieved by existing scale is also the largest.

(2) Provinces with inefficient scale of $R \& D$ and transformation functional platforms. These provinces belong to category II in the cluster analysis. Scale efficiency of R\&D and transformation functional platforms in these provinces is lower than that of pure technology. Guizhou, Inner Mongolia and Shaanxi belong to this category, accounting for $10 \%$ of the total. In the future, such provinces should expand platforms' scale in order to achieve scale effect.

(3) Provinces with low operating efficiency of R\&D and transformation functional platforms. These provinces belong to category III in the cluster analysis, pure technical efficiency and scale efficiency of R\&D and transformation functional platforms in these provinces are at a low level. A total of three provinces belong to this category, accounting for $10 \%$ of the total. Platforms operational efficiency in these provinces has much room to improve. On the one hand, the scale of platforms should be expanded to achieve scale effect; on the other hand, the investment of R\&D talents and R\&D funds should be increased to optimize the allocation of various input resources in order to improve the allocation efficiency.

(4) Provinces with inefficient configuration of R\&D and transformation functional platforms. These provinces belong to category IV in the cluster analysis, platforms' pure technical efficiency in these provinces is significantly lower than that of scale. Jilin, Guangxi, Heilongjiang, Hubei, Liaoning and Sichuan belong to this category, accounting for $20 \%$ of the total. In the future, such provinces should strengthen technological improvement efforts, optimize the allocation of platform resources input, and enhance pure technological efficiency.

\subsection{Input Improvement Plan}

After analyzing the operational efficiency of $R \& D$ and conversion functional platforms in 30 provinces, the main reasons for the ineffectiveness of $R \& D$ and conversion functional platforms are generally understood, mainly due to the poor proportion or redundancy of various types of inputs. To find out the best investment point, it is necessary to calculate the specific adjusting value of all kinds input when R\&D and transformation functional platform in provinces with ineffective DEA achieves DEA effectiveness. Calculate the slack variables in BCC model, and obtain the specific values of various input adjustments as shown in Table 8. 
Table 8. DEA Invalid Province R\&D and Transformation Functional Platform Input Adjustment.

\begin{tabular}{cccc}
\hline Province & $\begin{array}{c}\text { Total Number of Scientific } \\
\text { Researchers/Personnel }\end{array}$ & $\begin{array}{c}\text { Total Number of R\&D and Technical Service } \\
\text { Institutions/Piece }\end{array}$ & $\begin{array}{c}\text { Total R\&D } \\
\text { Investment/yuan }\end{array}$ \\
\hline Anhui & -34.14 & -7.66 & $-2,213,615.43$ \\
Jilin & -58.62 & -6.54 & $-1,952,174.26$ \\
Gansu & -30.18 & -3.02 & $-276,556.41$ \\
Guangxi & -64.32 & -9.43 & $-2,354,174.09$ \\
Guizhou & -26.17 & -2.25 & $-1,922,534.54$ \\
Heilongjiang & -17.34 & -6.73 & $-2,211,955.64$ \\
Hubei & -33.22 & -7.15 & $-2,316,739.74$ \\
Liaoning & -80.27 & -6.68 & $-1,597,794.63$ \\
Inner Mongolia & -97.48 & -9.87 & $-1,360,835.82$ \\
Qinghai & -86.25 & -11.27 & $-2,234,253.28$ \\
Sichuan & -39.69 & -8.14 & $-1,586,954.27$ \\
Xinjiang & -74.28 & -10.21 & $-1,362,745.13$ \\
\hline
\end{tabular}

In terms of R\&D human resources investment, there is no redundancy in the core R\&D personnel investment in 18 provinces. The average number of redundant R\&D personnel in the remaining 12 provinces is 53.50, which indicates that most R\&D and transformation functional platforms lack core R\&D personnel. Innovative R\&D activities involve technology research and development, results transformation, market development, process management and many other aspects, so it is necessary to staff institutions with relevant professionals to provide various services for the main body inside and outside the R\&D and transformation functional platform, however, whether large-scale scientific research institutes or transformation enterprises, there is a shortage of qualified personnel. For this reason, every year in the graduation season, these organizations will strive to find talent from Beijing to Silicon Valley, Harvard to MIT. Therefore, in the process of ensuring platforms' healthy and efficient operation, provinces must formulate a scientific and effective talent development strategies, establish a linkage mechanism between major R\&D projects and talent introduction, and increase the strength of introducing R\&D managerial talents and technological R\&D backbone from foreign and multinational enterprises.

In terms of R\&D and technical service organization, the average redundancy of R\&D and technical service organizations in 12 provinces was 7.41 . On the surface, it indicates the redundancy of $R \& D$ and technical service organizations in the platform, however, in practice, there have some problems in parts provinces, such as small scale of R\&D and technology service institutions, insufficient $R \& D$ and innovation resources, and difficulty in participating in R\&D and transformation activities. At present, $R \& D$ and transformation functional platforms in many provinces still provide basic services, lacking the ability to integrate and share all kinds of innovative $R \& D$ resources, ignoring the establishment of internal and external coordination mechanism, and lacking attractiveness to R\&D and technology service institutions, which leads to the large R\&D institutions with resources and strength are reluctant to join platform. In order to solve these problems, local governments should actively promote alliances and form an innovation transformation operation system dominated by core manufacturing enterprises. Strengthen the leading role of core enterprises, encourage enterprises, universities and scientific research institutions, financial institutions, intermediaries and other institutions in the system to derive more cooperative relations, and accelerate the formation and evolution of platform technology innovation ecosystem.

In terms of R\&D investment, the average redundancy in 12 provinces was 1,782,257.77 yuan, indicating that $R \& D$ and transformation functional platforms in these provinces invested more $R \& D$ funds. The large-scale output of independent R\&D technology needs to increase R\&D investment to improve R\&D capabilities, under 2025 Manufacturing Strategy, local government departments make every effort to support platform within the region, especially R\&D investment. At the present stage, the high financial subsidies and supporting policies of our government in the initial stage of $R \& D$ and transformation of functional platforms have made many platforms and internal subjects formed policy dependence, leading to some regional platforms living entirely on government subsidies 
and the R\&D and results transformation is lagging behind. Government investment should be the last choice for financing channels of R\&D and conversion functional platforms. Establishing and improving the financing service system of government coordination and guidance, bank cooperation support, financial service policy, and enterprise active participation is a more scientific and efficient way at present. First, establish a cooperation mechanism between the platform management department and bank, and promote the construction of technology guarantee system and technology financial service system. Second, establish a sound financial service policy. Third, make full use of innovative enterprises' self-owned funds, at the same time, establish a network for investment and financing under the leadership of government, explore the establishment of platform entities, banks, venture capital institutions, guarantee institutions, brokers, management consulting agencies and other interconnection mechanisms.

\subsection{Output Improvement Plan}

By calculating the relaxation variables in BCC model, the output types and quantities needed to increase in order to make the R\&D and transformation functional platforms of DEA ineffective provinces effective are obtained (see Table 9).

Table 9. DEA Invalid Province R\&D and Transformation Functional Platform Output Adjustment.

\begin{tabular}{ccccc}
\hline Province & $\begin{array}{c}\text { The Total Value of } \\
\text { Technical Achievements } \\
\text { Transformation/yuan }\end{array}$ & $\begin{array}{c}\text { Market Share of } \\
\text { Leading } \\
\text { Products/\% }\end{array}$ & $\begin{array}{c}\text { Output } \\
\text { Value of New } \\
\text { Products/\% }\end{array}$ & $\begin{array}{c}\text { Number of } \\
\text { Authorized Invention } \\
\text { Patents/Piece }\end{array}$ \\
\hline Anhui & 0 & 0 & 0 & 350.172 \\
Jilin & $1,239,652.17$ & 0.016 & 0.004 & 0 \\
Gansu & $2,038,947.33$ & 0 & 0 & 0 \\
Guangxi & 0 & 0 & 0.007 & 293.541 \\
Guizhou & $1,922,962.14$ & 0.014 & 0 & 220.612 \\
Heilongjiang & $2,801,957.32$ & 0 & 0.006 & 0 \\
Hubei & $1,882,996.53$ & 0 & 0 & 303.863 \\
Liaoning & 0 & 0 & 0 & 310.746 \\
Inner Mongolia & $2,288,776.81$ & 0.021 & 0 & 283.529 \\
Qinghai & $1,699,076.22$ & 0 & 0.002 & 0 \\
Sichuan & $1,776,234.58$ & 0.024 & 0 & 0 \\
Xinjiang & $2,288,199.25$ & 0 & 0.003 & 336.473 \\
\hline
\end{tabular}

In terms of the total value of technological achievements transformation, only nine provinces have room for further improvement, and the other 21 provincial platforms are in a relatively ideal state, which indicates that most provincial R\&D and transformation functional platforms in China have strong technology transformation capability. However, the actual research found that in terms of market share of leading products and output rate of new products, some platforms with strong transformation capabilities also need to work hard to improve transformation level. From the perspective of economics, the most ideal way to transform and promote technological achievements is to use market economy. The relationship between market supply and demand should be an important motive force to promote the technological transformation. On the other hand, establishing a market demand-oriented transformation model will help stimulate platform's innovation vitality, guide them to allocate resources around the market demand, solve the problem of disconnection between research and production, enhance the ability to connect and integrate innovative resources inside and outside the platform to support R\&D and transformation.

In terms of leading products market share, the R\&D and transformation functional platforms in the four provinces of Jilin, Guizhou, Inner Mongolia and Sichuan have insufficient market share. The technological achievements transformation is a continuous and procedural activity rather than a time-point behavior and state, effectively solving the integration of technology and market, building a number of institutions with technical evaluation, technical consultation, product promotion and other 
scientific and technological services as their main functions, and forming a network, professional and standardized service system for the media are the key to improving leading products market share.

In terms of the output rate of new products, Jilin, Guangxi, Heilongjiang, Qinghai and Xinjiang five provinces need to be upgraded. In addition to improve high-tech transformation capabilities, these platforms also need to improve the transformation process, establish a complete, smooth and diversified diffusion channel for technological innovation, and strengthen the diffusion of innovative technologies within the industry. Most importantly, government should actively assist in the establishment of a channel for technological innovation diffusion, connecting technology innovators and users of innovative technologies to form cross-regional and transnational technology intermediaries.

In terms of innovation efficiency, only seven province's platforms need to increase the number of authorized invention patents in that year, with an average increase of 299.848 pieces. This indicates that technological innovation level of R\&D and transformation functional platforms in most provinces shows a rapid development trend. To increase innovation benefits, increase patents are the key point, innovative manufacturing processes and innovative business models can also play an important role.

\section{Conclusions and Recommendations}

Based on the relevant operational data of $R \& D$ and transformation functional platforms in 30 provinces in 2018, the input, output and regional clustering of platform are calculated by DEA and $\mathrm{K}$-means clustering method. Overall, compared with the strategic requirements of the construction of global science and technology innovation center and the demand for technical services of industry development, there are still some problems and deficiencies in platform's development, such as weak $R \& D$ and transformation capacity, low market share of leading products, and insufficient capacity of new technology value-added. At the same time, the lack of information sharing and coordination network between $R \& D$ and transformation functional platforms leads to serious regional imbalances in platforms development: among the 30 provinces, 18 provinces belong to operation efficient provinces, three provinces belong to scale inefficient provinces, three provinces belong to operation inefficient provinces, six provinces belong to allocation inefficient provinces, from which we can see that there are significant differences in operation level among provinces. The results of input-output adjustment show that there are redundancies in $R \& D$ and transformation of functional platforms in a few provinces in terms of $R \& D$ personnel, research institutions and $R \& D$ input. In most provinces, $R \& D$ and transformation functional platforms have good performance in transformation capability, market share of leading products, output value of new products and number of patents for authorized inventions, which indicates that the overall operation of these platforms is good.

Aiming at the problems of platform's operation, input and output, the following policy suggestions are put forward:

(1) Rational planning and guidance

The platform development needs to gather internal and external forces, government's support is crucial. At different stages of platform system construction, government should assume different roles, such as planner, organizer, investor, leader and liaisons to promote platform's smooth development and optimization and upgrading. In the planning process, government should focus on promoting the design and popularization of innovation policies, strengthening the use of policy tools such as intellectual property rights, standards and taxation, and giving different development plans and future plans according to region's characteristics and the problems faced in platform operation. At the same time, government should handle the relationship with market correctly, take market as the orientation, focus on the construction of innovative environment, strengthen the overall design and coordination of innovation policy, and promote the transformation of policy from R\&D to the integrated design of innovation chain. 
(2) Scientific evaluation and optimization

Platforms should be as open and transparent as possible. This is not only conducive to the establishment of normal communications and communication mechanisms between the main bodies, ensuring that resources can be truly implemented in practice, and facilitating platform managers to evaluate and control beforehand, in-process and afterwards. At the same time, it also helps all high-tech industry associations, think tanks, research institutes and other organizations to conduct an overall evaluation of $R \& D$ and transformation functional platforms, and achieve comprehensive dynamic supervision and management of platform $R \& D$ and transformation activities. Platform evaluation should take innovation ability, transformation performance and social contribution as the main criteria. It should also design a reasonable income distribution mechanism for innovation teams and individuals based on the evaluation results to improve the attraction of high-level innovative talents.

(3) Enhancing exchanges and cooperation

Strengthen the construction of national R\&D and transformation functional platforms collaborative development network, encourage formal or informal communication between platforms to dredge channels for innovation and cooperation, and promote the sharing of R\&D and transformation resources and experiences within and among regions. Establish cross-regional R\&D and transformation functional platform alliances and associations, promote the flow of R\&D funds, core talents, transformation technology and other innovation and transformation elements among regions, realize the coordinated development of regional platforms and achieve win-win situation.

(4) Improving the operating environment

Strengthen platform's innovation ability. Firstly, optimize the learning environment of platform system, guide platform ecosystem to form an orderly competitive situation, promote the benign interaction between platforms, promote knowledge spillover and sharing, and change the situation of independent development of enterprises, universities and scientific research institutions. Second, strengthen innovation diffusion, establish channels for technology diffusion, connect technology innovators and users, and let technology users have a deeper understanding of the development prospects and advancement of technology. Third, improve standards and regulations, strengthen the protection of intellectual property rights and patented technologies, and establish information and data security management mechanisms.

(5) Accelerating the integration of resources

Improve the integration of various resource elements of R\&D and transformation functional platforms, improve open source awareness, and encourage relevant enterprises to cooperate with many researchers, developers and manufacturers around the world to create a basic resource sharing environment. Guide platform effectively utilizes the innovative resources of universities and research institutes through project cooperation, co-construction of $R \& D$ bases and innovation alliances to improve innovation capabilities. Strengthen cooperation and exchanges with foreign countries, based on the basic concepts of independent innovation and encouraging cooperation, step by step and selectively increase the opening up of science and technology programs. Accelerate the agglomeration of innovation subjects and the formation of innovation system, and reduce the barriers for innovation subjects outside the system to enter. Formulate talent flow policy, technology market cultivation policy and intellectual property protection policy to encourage the talent, information, technology and other resources flow within the system, thus forming a mechanism of resources smooth flow and knowledge sharing, and finally promoting the overall development of innovative ecosystem innovation capacity.

Author Contributions: All three authors contributed equally to gathering information, writing the manuscript, editing the manuscript and preparation of the figures. 
Funding: This research was funded by The National Natural Science Foundation of China (No. 71871134), Planning of Shanghai Soft Science (No. 17692103800; No. 18692104400), Key project of Anhui Province Social Sciences Innovative Development (No. 2018ZD013).

Conflicts of Interest: The authors declare no conflict of interest.

\section{References}

1. Adner, R. Match Your Innovation Strategy to Your Innovation Ecosystem. Harv. Bus. Rev. 2006, 84, 98-107. [PubMed]

2. Proskuryakova, L.; Meissner, D.; Rudnik, P. The use of technology platforms as a policy tool to address research challenges and technology transfer. J. Technol. Transfer 2017, 42, 206-227. [CrossRef]

3. Fraccascia, L.; Yazan, D.M. The role of online information-sharing platforms on the performance of industrial symbiosis networks. Resour. Conserv. Recycl. 2018, 136, 473-485. [CrossRef]

4. Berghe, L.; Van, D. The Strategic Value of New University Technology and Its Impact on Exclusivity of Licensing Transactions: An Empirical Study. Technol. Transfer 2008, 33, 91-103. [CrossRef]

5. Cai, N.W. The Rise of Self-organization and Platform Organization. Tsinghua Manag. Rev. 2015, 11, 70-76.

6. Armando, J.; Garcia, P. International trade and competitiveness. Econom. Theory 2012, 3, 727-763.

7. Choi, G.; Nam, C.; Kim, S. The impacts of technology platform openness on application developers' intention to continuously use a platform: From an ecosystem perspective. Telecommun. Policy 2019, 43, 140-153. [CrossRef]

8. Astyne, M.; Parker, G.; Choudary, S. Pipelines, platforms, and the new rules of strategy. Harv. Bus. Rev. 2016, 94, 90-97.

9. Mačiulienè, M.; Skaržauskienė, A. Evaluation of co-creation perspective in networked collaboration platforms. J. Bus. Res. 2016, 69, 4826-4830. [CrossRef]

10. Zhang, Y.; Luo, F.T. Research on the Operating Mechanism of Value-based Technology Achievement Conversion Service Platform. Sci. Technol. Prog. Countermeas. 2016, 33, 16-21.

11. Li, Y.; Zhang, Y.; Li, J. Research on Integrated Service Model of Regional Science and Technology Resources Platform from the Perspective of Evolution. China Sci. Technol. Forum 2017, 6, 51-57.

12. Yin, J.; Tan, Q.M. Operation mode of new industrial innovation platform under intelligent production and service network. Sci. Technol. Prog. Countermeas. 2018, 35, 65-69.

13. Wang, H.Q.; Su, P.; Wang, S.S. Regional platform based on strategic emerging industrial clusters. China Sci. Technol Forum. 2016, 32, 99-104.

14. Li, W.K.; Zhang, Y.; Wang, H.; Lu, W.Q.; Guo, B.H. Evolutionary Game Analysis of Technological Resource Platform and Innovation Behavior of Small and Medium-sized Enterprises under Dynamic Motivation. Ind. Eng. Manag. 2019, 6, 1-12.

15. Hu, Y.; Wen, J.Q.; Yan, Y. Measuring the performance of knowledge resources using a value perspective: Integrating BSC and ANP. J. Knowl. Manag. 2015, 19, 1250-1272. [CrossRef]

16. Hsiu, F. Linking knowledge management orientation to balanced scorecard outcomes. J. Knowl. Manag. 2015, 19, 1224-1249.

17. Yu, X.Y.; Wang, Y.K.; Li, Y.J. Enterprise Eco-strategy in VUCA era. Tsinghua Manag. Rev. 2018, 9, 68-74.

18. Cooke, P. From Clusters to Platform Policies in Regional Development. Eur. Plan. Stud. 2012, 20, 1415-1424. [CrossRef]

19. Boudreau, K. Open Platform Strategies and Innovation: Granting Access versus Devolving Control. Manag. Sci. 2010, 56, 849-872. [CrossRef]

20. Hernandez, G.; Allen, J.K.; Mistree, F. Platform Design for Customizable Products as a Problem of Access in a Geometric Space. Eng. Optim. 2003, 35, 229-254. [CrossRef] 